\title{
Metal accumulation in tobacco expressing Arabidopsis halleri metal hyperaccumulation gene depends on external supply
}

\author{
Anna Barabasz ${ }^{1}$, Ute Krämer ${ }^{2}$, Marc Hanikenne ${ }^{3}$, Justyna Rudzka ${ }^{1}$ and Danuta Maria Antosiewicz ${ }^{1, *}$ \\ 1 University of Warsaw, Faculty of Biology, Institute of Experimental Plant Biology, Miecznikowa Street 1, 02-096 Warszawa, Poland \\ 2 Lehrstuhl für Pflanzenphysiologie, Ruhr-Universität Bochum, Universitätsstrasse 150, D-44801 Bochum, Germany \\ ${ }^{3}$ Max Planck Institute of Molecular Plant Physiology, D-14476 Potsdam, Germany \\ * To whom correspondence should be addressed: E-mail: dma@biol.uw.edu.pl
}

Received 22 February 2010; Revised 22 April 2010; Accepted 22 April 2010

\begin{abstract}
Engineering enhanced transport of zinc to the aerial parts of plants is a major goal in bio-fortification. In Arabidopsis halleri, high constitutive expression of the AhHMA4 gene encoding a metal pump of the $\mathrm{P}_{1 \mathrm{~B}}$-ATPase family is necessary for both $\mathrm{Zn}$ hyperaccumulation and the full extent of $\mathrm{Zn}$ and $\mathrm{Cd}$ hypertolerance that are characteristic of this species. In this study, an AhHMA4 cDNA was introduced into $N$. tabacum var. Xanthi for expression under the control of its endogenous $A$. halleri promoter known to confer high and cell-type specific expression levels in both $A$. halleri and the non-hyperaccumulator $A$. thaliana. The transgene was expressed at similar levels in both roots and shoots upon long-term exposure to low $\mathrm{Zn}$, control, and increased $\mathrm{Zn}$ concentrations. A down-regulation of AhHMA4 transcript levels was detected with $10 \mu \mathrm{M} Z n$ resupply to tobacco plants cultivated in low $\mathrm{Zn}$ concentrations. In general, a transcriptional regulation of AhHMA4 in tobacco contrasted with the constitutively high expression previously observed in $\mathrm{A}$. halleri. Differences in root/shoot partitioning of $\mathrm{Zn}$ and $\mathrm{Cd}$ between transgenic lines and the wild type were strongly dependent on metal concentrations in the hydroponic medium. Under low $\mathrm{Zn}$ conditions, an increased $\mathrm{Zn}$ accumulation in the upper leaves in the AhHMA4-expressing lines was detected. Moreover, transgenic plants exposed to cadmium accumulated less metal than the wild type. Both modifications of zinc and cadmium accumulation are noteworthy outcomes from the biofortification perspective and healthy food production. Expression of AhHMA4 may be useful in crops grown on soils poor in $\mathrm{Zn}$.
\end{abstract}

Key words: AhHMA4, Arabidopsis halleri, cadmium, $\mathrm{P}_{1 \mathrm{~B}}$ ATPase, tobacco, transformation, zinc.

\section{Introduction}

Current knowledge on the molecular and biochemical mechanisms of transition metal homeostasis in plants is commonly used in attempts to modify metal uptake, rootto-shoot translocation, and distribution at the cellular, tissue, and organ levels. Such alterations are a focus in both phytoremediation and biofortification, although the needs in these two applications are different. In phytoremediation (phytoextraction) the aim is to increase the uptake from contaminated sites, translocation to shoots, accumulation and the level of tolerance to metals of interest for soil cleanup (Kunze et al., 2002; Krämer, 2005; Zhao and McGrath, 2009). Biofortification aims at an efficient micronutrient uptake mainly from poor soils, and an efficient trans- location to the edible parts of crop plants (Krämer et al., 2007; Palmgren et al., 2008; Krämer, 2009). The common goal, however, for both biotechnological applications is to increase the transfer of metals from the roots to the shoots. Genetic engineering is a promising tool in both applications.

As a micronutrient necessary for maintaining basic physiological processes, zinc is essential in plants, animals, and humans. However, it is frequently deficient in the diet, resulting in poor health. Across the world, there are many soils that are $\mathrm{Zn}$-deficient or with low $\mathrm{Zn}$ bioavailability. Consequently, crops cultivated there contain low $\mathrm{Zn}$ concentrations leading to $\mathrm{Zn}$-deficiency-based malnutrition. 
There are also areas with extremely high soil $\mathrm{Zn}$ levels. It is well known that an excess of $\mathrm{Zn}$ is toxic, and phytoremediation is considered the only way to clean up soils contaminated with metals (Pilon-Smits and Pilon, 2002; Verkleij et al., 2009; Zhao and McGrath, 2009). Altogether, there is a strong need to elaborate the way of engineering of enhanced $\mathrm{Zn}$ uptake and accumulation in the shoots.

Knowledge on the mechanisms that control the root-toshoot translocation of zinc and other transition metals is still rudimentary. Only recently, studies performed by several research groups reported the involvement of $H M A 4$, which encodes a $\mathrm{P}_{1 \mathrm{~B}}$-ATPase, both from $A$. thaliana (Mills et al., 2003, 2005; Hussain et al., 2004; Verret et al., 2004, 2005) and $A$. halleri (Hanikenne et al., 2008) primarily in the transport of $\mathrm{Zn}$, but also $\mathrm{Cd}$, to the shoots. In $A$. halleri, a $\mathrm{Zn} / \mathrm{Cd}$-hyperaccumulating species, AhHMA4 is required for highly efficient root-to-shoot transport and thus for shoot $\mathrm{Zn}$ hyperaccumulation (Hanikenne et al., 2008). HMA4 transcript levels are much higher in $A$. halleri than in $A$. thaliana, although HMA4 expression localizes largely to the same cell types in both species. It was shown that the A. halleri HMA4 promoter governs high expression levels of AhHMA4 or a reporter gene in both the A. halleri and the $A$. thaliana genetic backgrounds (Hanikenne et al., 2008). In the closely related non-accumulating A. thaliana, $A t \mathrm{HMA} 4$ and the homologous AtHMA2 control $\mathrm{Zn} / \mathrm{Cd}$ translocation to the aerial parts of the plant, and their general role is to maintain $\mathrm{Zn}$-dependent processes in the shoot (Hussain et al., 2004; Wong and Cobbett, 2009). Interestingly, the overexpression of $A h H M A 4 \mathrm{cDNA}$ under the control of its native promoter in $A$. thaliana was sufficient to recapitulate the radial $\mathrm{Zn}$ distribution pattern typical of $A$. halleri roots, with increased $\mathrm{Zn}$ concentrations in the xylem vessels (Hanikenne et al., 2008).

Here, tobacco was transformed with a construct containing the AhHMA4 cDNA downstream of its native promoter from $A$. halleri in an attempt to engineer more efficient root-to-shoot $\mathrm{Zn}$ translocation and thus enhanced accumulation in the shoots of an agricultural plant. The use of the same construct for tobacco transformation as for the transformation of $A$. thaliana (Hanikenne et al., 2008) allowed us to examine: whether the endogenous $A$. halleri $H M A 4$ promoter (i) is effectively conferring expression of AhHMA4 in tobacco; and (ii) confers root and shoot expression patterns in tobacco similar to those in Arabidopsis. In addition, it was tested whether expression of AhHMA4 in tobacco (iii) generates modifications in $\mathrm{Zn}$ partitioning as observed in $A$. thaliana and (iv) can alter metal tolerance. Tobacco was chosen as a model plant for the heterologous expression because it is easy to transform and regenerate.

\section{Materials and methods}

Transformation

AhHMA4-1, one of the three AhHMA4 gene copies that are constitutively very highly expressed in the $\mathrm{Zn} / \mathrm{Cd}$ hyperaccumula- tor Arabidopsis halleri was used in this study. The construct which was generated and used previously by Hanikenne et al. (2008) for the transformation of $A$. thaliana was used here for the transformation of tobacco (Nicotiana tabacum var. Xanthi).

The standard procedure (Murashige and Skoog, 1962; Horsch et al., 1985) of Agrobacterium-mediated transformation of leaf discs of tobacco (seeds from the stock of the Institute of Biochemistry and Biophysics PAS, Warszawa, Poland) was applied as described in Antosiewicz and Hennig (2004). Transgenic plants were selected on medium supplemented with $25 \mu \mathrm{M}$ hygromycin. $\mathrm{T}_{1}$ seeds were collected from the $\mathrm{T}_{0}$ generation that was confirmed for the presence of AhHMA4 cDNA sequence by PCR and mRNA expression by RT-PCR. The primer sequences and the reaction conditions are given in the sub-section 'Determination of Cd-tolerance and accumulation'.

As a result of the transformation, 22 independent transgenic lines were selected. The segregation ratio of hygromycin-resistant to hygromycin-sensitive $T_{1}$ plants, determined for all of them, was found to be 3:1 (tolerant:sensitive) for 10 lines, indicating a singlelocus insertion of the transgene.

\section{Plant material and general growth conditions}

Tobacco wild type (Nicotiana tabacum var. Xanthi) and independently transformed lines were included in the experiments. Six heterozygous $\mathrm{T}_{1}$ lines with a $3: 1$ hyg $^{\mathrm{R}}$ :hyg ${ }^{\mathrm{S}}$ segregation ratio were selected at random (nos 2, 10, 23, 27, 28, and 35). The expression of the transgene was determined, and three lines with differing levels of AhHMA4 expression (low and high) were used to obtain homozygous $\mathrm{T}_{2}$ plants (nos 2, 28, and 35; details in the Results, section 'Tobacco expressing AhHMA4 $_{p 1}:$ :AhHMA4'). Depending on the experiment, heterozygous and/or homozygous lines were used (details in the Results and in the figure legend).

All experiments were carried out in a growth chamber, at $23 / 16{ }^{\circ} \mathrm{C}$ day/night temperatures, $40-50 \%$ constant humidity, with a $16 \mathrm{~h}$ photoperiod at a quantum flux density (PAR) of $250 \mu \mathrm{mol}$ $\mathrm{m}^{-2} \mathrm{~s}^{-1}$ using fluorescent Flora tubes. Seeds were surface-sterilized in $8 \%(\mathrm{v}: \mathrm{v})$ sodium hypochloride for $2 \mathrm{~min}$ and germinated on Petri dishes positioned vertically, containing quarter-strength Knop's medium supplemented with $2 \%(\mathrm{w} / \mathrm{v})$ sucrose and solidified with $1 \%$ (w/v) agar (Wojas et al., 2008). To germinate seeds of the $\mathrm{T}_{1}$ heterozygous generation, $10 \mu \mathrm{M}$ hygromycin was added to the medium described above to select transgenic plants for the experiments. Seedlings were grown for 3 weeks on agar plates and subsequently transferred to 2.41 pots ( 6 plants per pot) containing aerated quarter-strength Knop's solution with modified concentrations of cadmium and zinc, as indicated in the sub-section 'Experiments using a different Zn supplies'. The nutrient solution was changed every four days (unless indicated otherwise). The composition of the quarter-strength Knop's medium is as follows: $0.75 \mathrm{mM} \mathrm{Ca}\left(\mathrm{NO}_{3}\right)_{2}, 0.375 \mathrm{mM} \mathrm{KNO}_{3}, 0.312 \mathrm{mM} \mathrm{MgSO}_{4}$, $0.25 \mathrm{mM} \mathrm{KH} \mathrm{KO}_{4}$, microelements: $10 \mu \mathrm{M}$ NaFeEDTA, $6.25 \mu \mathrm{M}$ $\mathrm{H}_{3} \mathrm{BO}_{3}, 0.5 \mu \mathrm{M} \mathrm{MnCl}_{2}, 0.5 \mu \mathrm{M} \mathrm{ZnSO}_{4}, 0.025 \mu \mathrm{M} \mathrm{CuSO}_{4}$, $0.125 \mu \mathrm{M} \mathrm{Na} \mathrm{MoO}_{4}, 1.25 \mu \mathrm{M} \mathrm{KJ}, 0.025 \mu \mathrm{M} \mathrm{CoCl}$. This medium was used as a basic reference (control) medium in parallel to all $\mathrm{Zn}$ and $\mathrm{Cd}$ treatments. Since the experiments included testing the plant response to low $\mathrm{Zn}$, the medium without $\mathrm{Zn}$ addition was determined by ICP-MS to contain on average $0.4 \pm 0.03 \mu \mathrm{M}$ zinc (arithmetic mean $\pm \mathrm{SD} ; n=3$ ). All applied zinc concentrations used in this study are shown as the final (total) concentration present in the medium.

\section{Experiments using a different $Z n$ supply}

The response of tobacco seedlings to various zinc concentrations was tested in four types of experiment performed under hydroponic conditions. As a control and reference, quarter-strength Knop's medium containing a total of $0.9 \mu \mathrm{M} \mathrm{ZnCl} \mathrm{Zn}_{2}$ was used in parallel to all treatments. Three-week-old seedlings were transferred from the agar plates (as described in the section, 'Plant 
material and general growth conditions') to hydroponic solutions and subjected to the following treatments. (i) Long-term low $\mathrm{Zn}$ treatment: pre-culture in control medium for 1 week, then growth in medium containing $0.4 \mu \mathrm{M} \mathrm{ZnCl} 2$ for 5 weeks. (ii) Low $\mathrm{Zn}$ followed by re-supply with moderately high $\mathrm{Zn}$ : pre-culture on control medium for 2 weeks, followed by 1 week of exposure to $0.4 \mu \mathrm{M} \mathrm{Zn}$ and $1 \mathrm{~d}$ exposure to $10 \mu \mathrm{M} \mathrm{Zn}$. (iii) Moderately high $\mathrm{Zn}$ concentration: growth on the control medium supplemented with $10 \mu \mathrm{M} \mathrm{Zn}$ for 3 weeks. (iv) High $\mathrm{Zn}$ : pre-culture on control medium for 3.5 weeks followed by growth in a medium containing toxic $\mathrm{Zn}$ concentrations of 150 and $500 \mu \mathrm{M} \mathrm{Zn}$ for $8 \mathrm{~d}$ (during the exposure to high $\mathrm{Zn}$ the medium was changed every second day).

At the end of each experiment, plant health (the presence of necrosis, the colour of the leaf blades, etc.) was assessed visually and plant material was harvested for further analysis ( $\mathrm{Zn}$ accumulation, gene expression).

\section{Determination of Cd-tolerance and accumulation}

Seedlings transferred from the agar plates were pre-cultured on control liquid medium for 3.5 weeks, then exposed to 0.25 and $4 \mu \mathrm{M} \mathrm{CdCl} 2$ for between $1 \mathrm{~d}$ and $8 \mathrm{~d}$ as indicated. During the exposure period, the medium was changed every second day. At the end of the exposure period, roots and shoots were harvested for further analysis ( $\mathrm{Cd}$ accumulation, gene expression).

\section{Determination of AhHMA4 and NtIRT1 expression}

Material (roots, and 4th and 5th leaves from the top) was harvested for the analysis of gene expression, frozen in liquid nitrogen and stored at $-80{ }^{\circ} \mathrm{C}$. The expression level of $A h H M A 4$ was evaluated in the roots of six heterozygous transgenic plant lines in the $T_{1}$ generation (nos 2, 10, 23, 27, 28, and 35) after cultivation in control liquid medium for 3 weeks. In more detailed studies, expression was then determined in the roots and leaves of two representative homozygous transgenic lines (nos 2 and 35) grown under the following conditions (details for $\mathrm{Zn}$ treatment described in the sub-section 'Experiments using a different $\mathrm{Zn}$ supplies'; for cadmium treatment in the sub-section 'Determination of Cd-tolerance and accumulation'): (i) under control conditions; (ii) under long-term $\mathrm{Zn}$-deficiency; (iii) under $\mathrm{Zn}$ deficiency/resupply experiment; (iv) in the presence of $10 \mu \mathrm{M} \mathrm{Zn}$; (v) in the presence of 0.25 and $4 \mu \mathrm{M} \mathrm{Cd}$ ( $24 \mathrm{~h}$ exposure).

The expression level of NIIRTI was determined in the roots and leaves of homozygous transgenics (lines 2 and 35) and control plants in the experiments described above marked (i)-(iv).

Approximately $100 \mathrm{mg}$ of frozen tissue of hydroponically grown plants was used for RNA extraction using the RNeasy Plant Mini-Kit (Qiagen), following the manufacturer's recommendations. The RT-PCR was performed as described by Wojas et al. (2007). The following primers were used for PCR (30 cycles): (i) for AhHMA4-1 (GenBank accession number EU 382073): forward: 5'-ACGGGGACAGTGAAACAAAG-3'; reverse: 5' TGCATAACTCCTGCAACAGC-3' (product $588 \mathrm{bp}$ ); (ii) for NtIRT1 (GenBank accession no. AB263746): forward: 5' GTTGTCGTCCAGTTGCTTGA-3'; reverse: 5'-AGAATGCAACCACCAAGTCC-3' (product 438 bp). (iii) for Actin (used as a control; NtTac9, GenBank accession no. X69885): forward: 5'-CCTCCCACATGCTATTCTCC-3'; reverse: 5'-AGAGCCTCCAATCCAGACAC-3' (product 523 bp).

\section{Measurements of $\mathrm{Zn}$ and $\mathrm{Cd}$ accumulation}

$\mathrm{Zn}$ and $\mathrm{Cd}$ concentrations were assessed: (i) in the whole roots and shoots of plants from all treatments described in the sub-section, 'Determination of AhHMA4 and NtIRT1 expression', except for long-term Zn-deficiency plants; (ii) in long-term Zn-deficiency plants in the whole roots as well as in separated parts: stems and three groups of leaves (out of a total number of leaves of 14 to 15), counting from the top; $(*)$ upper five leaves; $(* *)$ four to five middle leaves; $(* * *)$ five lower leaves. Plant parts were collected (as indicted above) at the end of each experiment. Roots were washed in water and then, to remove unbound and weakly bound metal from the apoplast, desorbed in $5 \mathrm{mM} \mathrm{CaCl}_{2}$ at $4{ }^{\circ} \mathrm{C}$ for $15 \mathrm{~min}$, and again washed in water. Plant samples were dried at $55^{\circ} \mathrm{C}$ in an oven for $4 \mathrm{~d}$, and dry biomass was determined. Dried plant material was mineralized in $65 \% \mathrm{HNO}_{3}$ and $39 \% \mathrm{H}_{2} \mathrm{O}_{2}(9: 1, \mathrm{v}: \mathrm{v})$ in a closed system microwave mineralizer (Milestone Ethos 900, Milestone, Bergamo, Italy) (Antosiewicz, 2005; Wojas et al., 2009). Cadmium and zinc concentrations were determined by flame atomic absorption spectrophotometry (TJA Solution Solar M, Thermo Electron Manufacturer Ltd., Cambridge, Great Britain). Certified reference material (Virginia tobacco leaves CTA-VTL-2; Commission for Trace Analysis of the Committee for Analytical Chemistry PAS and Institute of Nuclear Chemistry and Technology, Warsaw) was included in each analysis run.

\section{Statistical analysis}

All data are expressed as arithmetic means \pm SD of replicate plants within an experiment. All data shown are from one experiment representative of a total of two to four independent biological experiments. Statistical significance was evaluated at the 0.05 probability level using Student's $t$ tests. Analysis was performed with Excel 2003 for Windows.

\section{Results}

\section{Tobacco expressing AhHMA4 ${ }_{p 1}:: A h H M A 4$}

Six-week old plants of six representative heterozygous plant lines of the $T_{1}$ generation exhibiting a $3: 1$ hyg $^{\mathrm{R}}$ hyg $^{\mathrm{S}}$ segregation ratio and cultivated under control conditions were tested for the expression of AhHMA4 in their roots. They all expressed the transgene, although at different levels (Fig. 1). Transgenic plants cultivated on control medium did not differ from the wild-type plants in their appearance and development (data not shown).

\section{AhHMA4 expression modifies $Z n$ accumulation and decreases $Z n$-tolerance}

Exposure to control, moderately high and high zinc concentrations: Upon growth at $0.9 \mu \mathrm{M} \mathrm{Zn}$ (control conditions), shoot $\mathrm{Zn}$ concentrations were between $23 \%$ and $35 \%$ lower in transgenic tobacco lines than in wild-type plants, and there was a general trend for slightly lower root $\mathrm{Zn}$ concentrations, although this was only statistically significant in two lines (Fig. 2A, B). Upon cultivation at a moderately high, non-toxic $\mathrm{Zn}$ concentration of $10 \mu \mathrm{M}$,

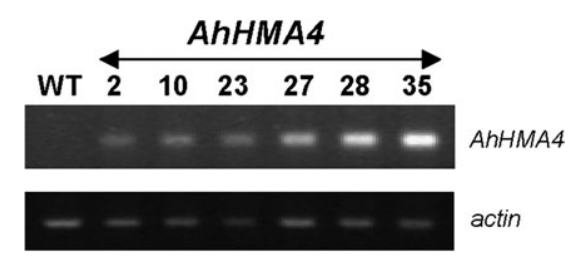

Fig. 1. RT-PCR analysis of transcript levels of AhHMA4. Representative results are shown for independent heterozygous transgenic lines of the $T_{1}$ generation of plants grown on control medium for 3 weeks. Bottom panels shows the PCR product for actin as a constitutively expressed control gene. WT, wild type. 

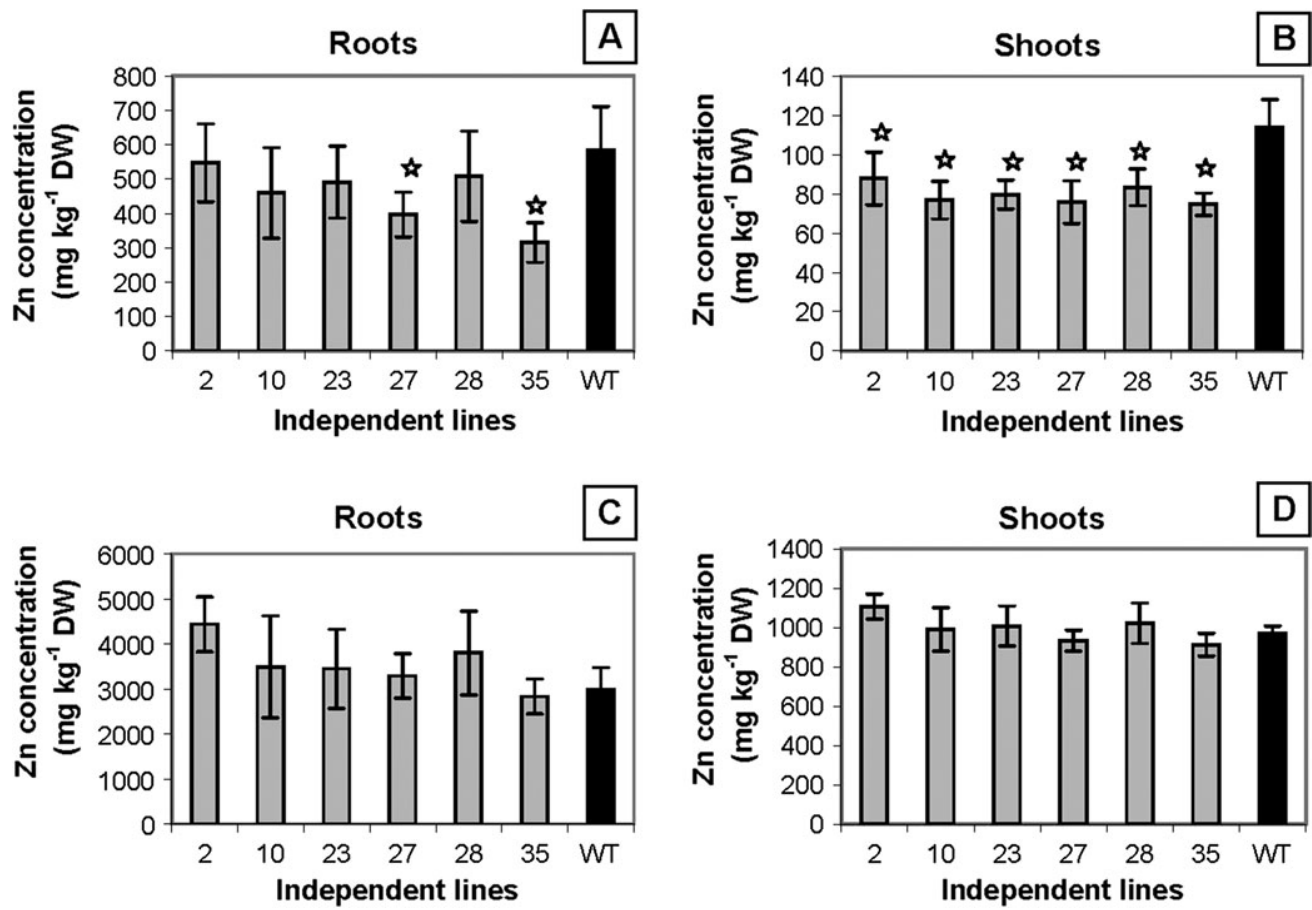

Fig. 2. Zinc accumulation in tobacco plants transformed with AhHMA4-transformed and wild-type tobacco lines cultivated in control Zn conditions and in a moderate, non-toxic excess of Zn. Values represent $Z n$ concentrations in the roots $(A, C)$ and the shoots (B, D) of 6week-old tobacco plants grown hydroponically in quarter-strength Knop's medium containing $0.9 \mu \mathrm{M} \mathrm{ZnCl}_{2}(\mathrm{~A}, \mathrm{~B})$ or $10 \mu \mathrm{M} \mathrm{ZnCl} 2(\mathrm{C}, \mathrm{D})$ for 3 weeks. Lines 10, 23, and 27 are heterozygous $\left(T_{1}\right)$; lines 2, 28, and 35 are homozygous $\left(T_{2}\right)$. Values correspond to arithmetic means \pm SD $(n=5)$; values significantly different from WT are highlighted by an asterisk $(P \leqslant 0.05)$ (evaluated by Student's $t$ test).

$\mathrm{Zn}$ concentrations were equivalent in transgenic and wildtype plants in both shoots and roots (Fig. 2C, D). Expression of AhHMA4 in tobacco did thus not result in enhanced shoot $\mathrm{Zn}$ accumulation under the conditions used. It is worth noting that $\mathrm{Zn}$ concentration in plants from heterozygous lines of the $T_{1}$ generation (nos 10,23, and 27) was at the same level as in homozygous lines of the $T_{2}$ generation (nos 2, 28, and 35) (Fig. 2). The response of plants to very high, toxic $\mathrm{Zn}$ concentrations was tested only on homozygous lines. In plants exposed to high, toxic concentrations of 150 and $500 \mu \mathrm{M} \mathrm{Zn}$, again no difference in $\mathrm{Zn}$ accumulation was observed between transformed and wild-type plants (Fig. 3). At the end of the period of cultivation at toxic $\mathrm{Zn}$ concentrations, transformant lines exhibited a larger number of necrotic spots within the leaf blades than the wild type (Fig. 4A-D). Thus, symptoms of $\mathrm{Zn}$ toxicity were more severe in AhHMA4-expressing plants.

Long-term low Zn treatment: Wild-type plants and transgenic lines grown for 5 weeks in medium containing $0.4 \mu \mathrm{M}$ $\mathrm{Zn}$ displayed similar symptoms. They all had lower fresh biomass relative to the control plants cultivated in control medium ( $\%$ of fresh biomass of plants of the same line grown in control conditions: $77.8 \pm 11.4 \%$ for the wild type; $83.9 \pm 15.8 \%$ for line no. $2 ; 84.3 \pm 13.2 \%$ for line no. 35 ), without significant differences between transgenics and the wild type (data not shown). In all plants grown on low-zinc medium, stems were shorter but the number of leaves (there were between 14 and 15) remained the same as in the plants grown in control conditions, whereby the three to four lowest leaves were yellow in colour (data not shown). In contrast to the wild-type plants, $\mathrm{Zn}$ concentration in the upper leaves of transgenic lines was significantly higher than in the middle and lower leaves (Fig. 5). In addition, $\mathrm{Zn}$ concentration in the upper leaves was higher than in the wild type (significantly higher in line no. 35). However, the comparison of the total $\mathrm{Zn}$ concentration demonstrates only its tendency to be higher in transgenic plants. In tobacco, expression of AhHMA4 specifically enhanced $\mathrm{Zn}$ accumulation in the youngest, rapidly growing leaves.

\section{AhHMA4 expression in tobacco decreases Cd accumulation and Cd tolerance}

Upon exposure to a low $\mathrm{Cd}$ concentration of $0.25 \mu \mathrm{M}$, root Cd concentrations in AhHMA4-expressing lines were, on average, only $50 \%$ of those in control plants (Fig. 6A). Shoot $\mathrm{Cd}$ concentrations were similar in wild type and transgenic lines (Fig. 6B) resulting in an average of 1.8-fold higher shoot:root $\mathrm{Cd}$ concentration ratios in the transgenic lines, both when heterozygous (nos 10, 23, and 27) and homozygous (nos 2, 28, and 35), (Fig. 6C). Under this condition, none of the plants exhibited any visual symptoms of cadmium toxicity (data not shown). When plants were exposed to higher $\mathrm{Cd}$ concentrations of $4 \mu \mathrm{M}$, the differences in Cd partitioning between AhHMA4-expressing and 

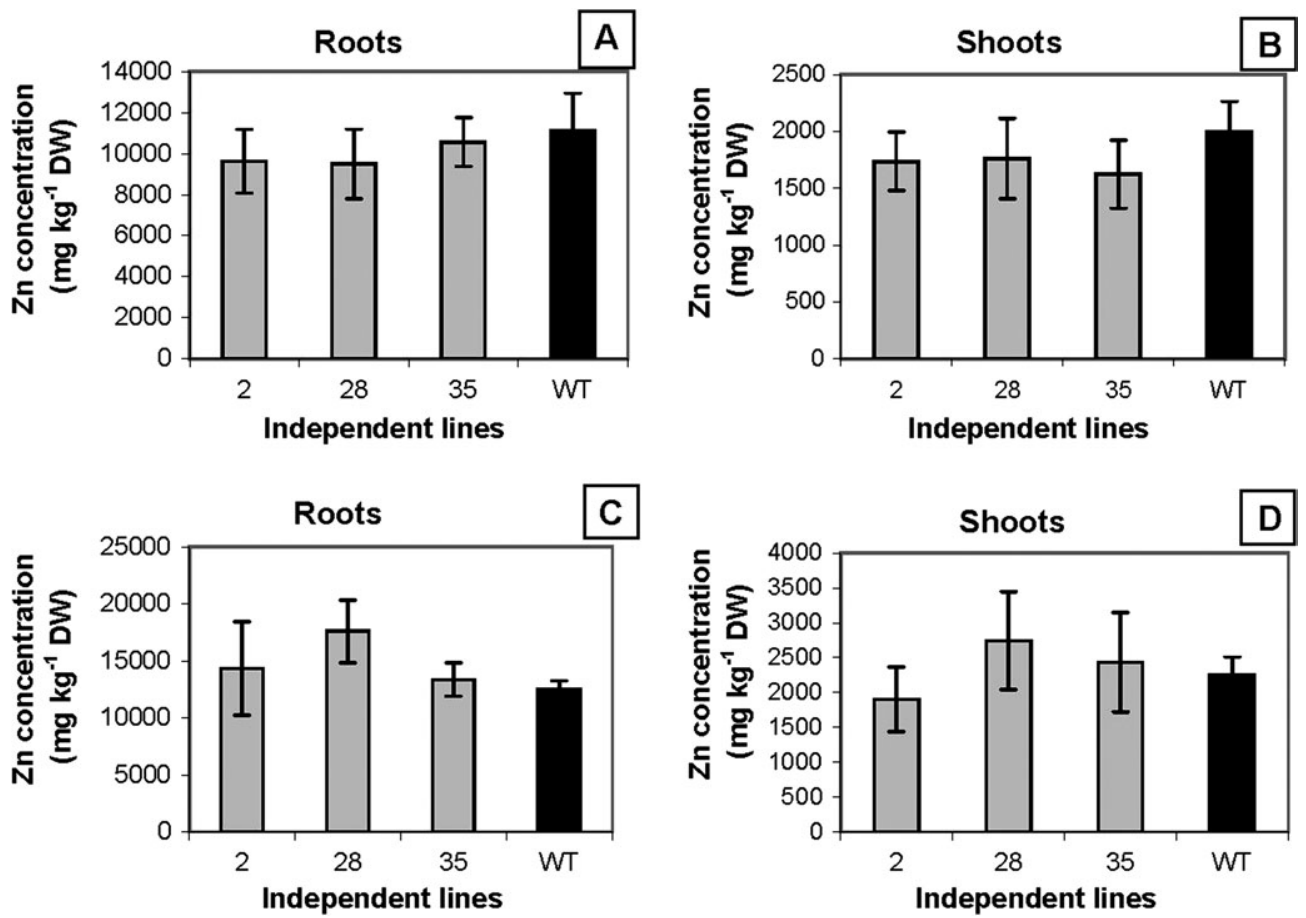

Fig. 3. Zinc accumulation in wild-type and homozygous AhHMA4-transformed tobacco lines upon growth in high Zn concentrations. Values are concentrations in roots (A, C) and shoots (B, D) of 6-week-old tobacco plants transformed with AhHMA4 (homozygous lines, $\mathrm{T}_{2}$ generation) and of wild-type (WT) tobacco (var. Xanthi) grown hydroponically in quarter-strength Knop's medium for 3.5 weeks and subsequently exposed to $150 \mu \mathrm{M} \mathrm{ZnCl} 2$ (A, B) or $500 \mu \mathrm{M} \mathrm{ZnCl}$ (C, D) for $8 \mathrm{~d}$. Values correspond to arithmetic means $\pm \mathrm{SD}(n=5)$; no statistically significant differences were detected between WT and transgenic lines (evaluated by Student's $t$ test).

wild-type plants were quantitatively much less pronounced although qualitatively similar as observed upon exposure to $0.25 \mu \mathrm{M}$ Cd (compare Fig. 6D-F with A-C).

Expression of AhHMA4 in tobacco did not increase $\mathrm{Cd}$ tolerance. The number of necrotic spots on the leaves of transgenic plants exposed to $4 \mu \mathrm{M} \mathrm{Cd}$ was similar or slightly higher when compared with the wild type (Fig. 4E, F).

\section{The AhHMA4 $4_{p 1}::$ AhHMA4 construct is expressed under different $Z n$ and $C d$ conditions}

Heterologous introduction of AhHMA4 under its endogenous promoter into the tobacco genome raises some fundamental questions: (i) is it expressed? (ii) is it regulated in response to metal supply? To test this, the expression level of AhHMA4 was assessed in two plant lines (nos 2 and 35 ) grown hydroponically in the presence of a range of zinc and cadmium concentrations.

As shown in Fig. 7, AhHMA4 was expressed at similar levels after 4-5 weeks of growth at $0.4,0.9$, and $10 \mu \mathrm{M} \mathrm{Zn}$ in both the leaves and roots of lines 2 and 35 (Fig. 7A, B). However, $24 \mathrm{~h}$ of resupply of $10 \mu \mathrm{M} \mathrm{Zn}^{2+}$ to plants grown in a low $\mathrm{Zn}$ concentration of $0.4 \mu \mathrm{M} \mathrm{Zn}$ for 1 week (Fig. 8) resulted in the down-regulation of AhHMA4 transcript levels in roots when compared with plants grown in low $\mathrm{Zn}$ $(0.4 \mu \mathrm{M} \mathrm{Zn})$ for 1 week. By contrast, in leaves, the expression level remained unchanged.

Different $\mathrm{Cd}$ concentrations in the medium had no effect on transcript levels in either roots or leaves (Fig. 9).

\section{AhHMA4 expression contributes to alterations of IRT1 expression under Zn exposure}

Expression of AhHMA4 in tobacco led to contrasting changes in $\mathrm{Zn}$ accumulation, which were dependent on the $\mathrm{Zn}$ concentrations in the medium. However, in tobacco, AhHMA4 was expressed in both roots and shoots under all conditions tested, and transcript levels were altered only in comparisons between low $\mathrm{Zn}$ plants and those resupplied with $10 \mu \mathrm{M} \mathrm{Zn} \mathrm{(Figs} \mathrm{7,} \mathrm{8,} \mathrm{9).} \mathrm{Therefore,} \mathrm{it} \mathrm{was} \mathrm{tested}$ whether AhHMA4 transgene expression affects the expression of an endogenous tobacco gene known to contribute to $\mathrm{Zn}$ accumulation. NtIRTl was chosen as a candidate gene because it acts as a multi-substrate cation transporter that contributes to root uptake of $\mathrm{Fe}^{2+}, \mathrm{Zn}^{2+}, \mathrm{Cd}^{2+}, \mathrm{Mn}^{2+}$, and $\mathrm{Co}^{2+}$ ions and is similar with the homologues from $A$. thaliana and O. sativa (Korshunova et al., 1999; Connolly et al., 2002; Hodoshima et al., 2008; Lee and An, 2009).

As expected, NtIRTl was not expressed in leaves (data not shown). However, the transcript was detected in all root samples (Fig. 7B). In wild-type plants, NtIRT1 transcript levels remained at similar levels under all $\mathrm{Zn}$ treatments. By contrast, in AhHMA4-expressing transgenics, compared with control conditions, NtIRTI mRNA levels were increased under low $\mathrm{Zn}$ and, surprisingly, also upon growth at $10 \mu \mathrm{M} \mathrm{Zn}$. Under control conditions, NtIRT1 transcript levels were similar in both wild-type and transgenic plants. Compared with plants exposed to low $0.4 \mu \mathrm{M} \mathrm{Zn}$, a resupply of $10 \mu \mathrm{M} \mathrm{Zn}$ for $1 \mathrm{~d}$ to plants grown in low-Zn conditions 


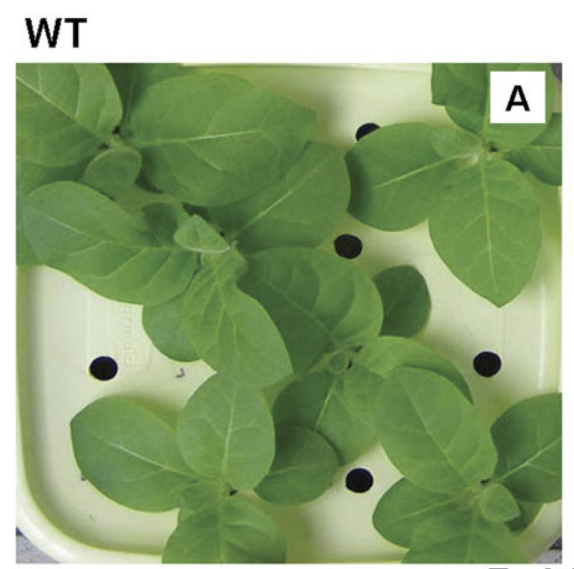

AhHMA4 \# 35
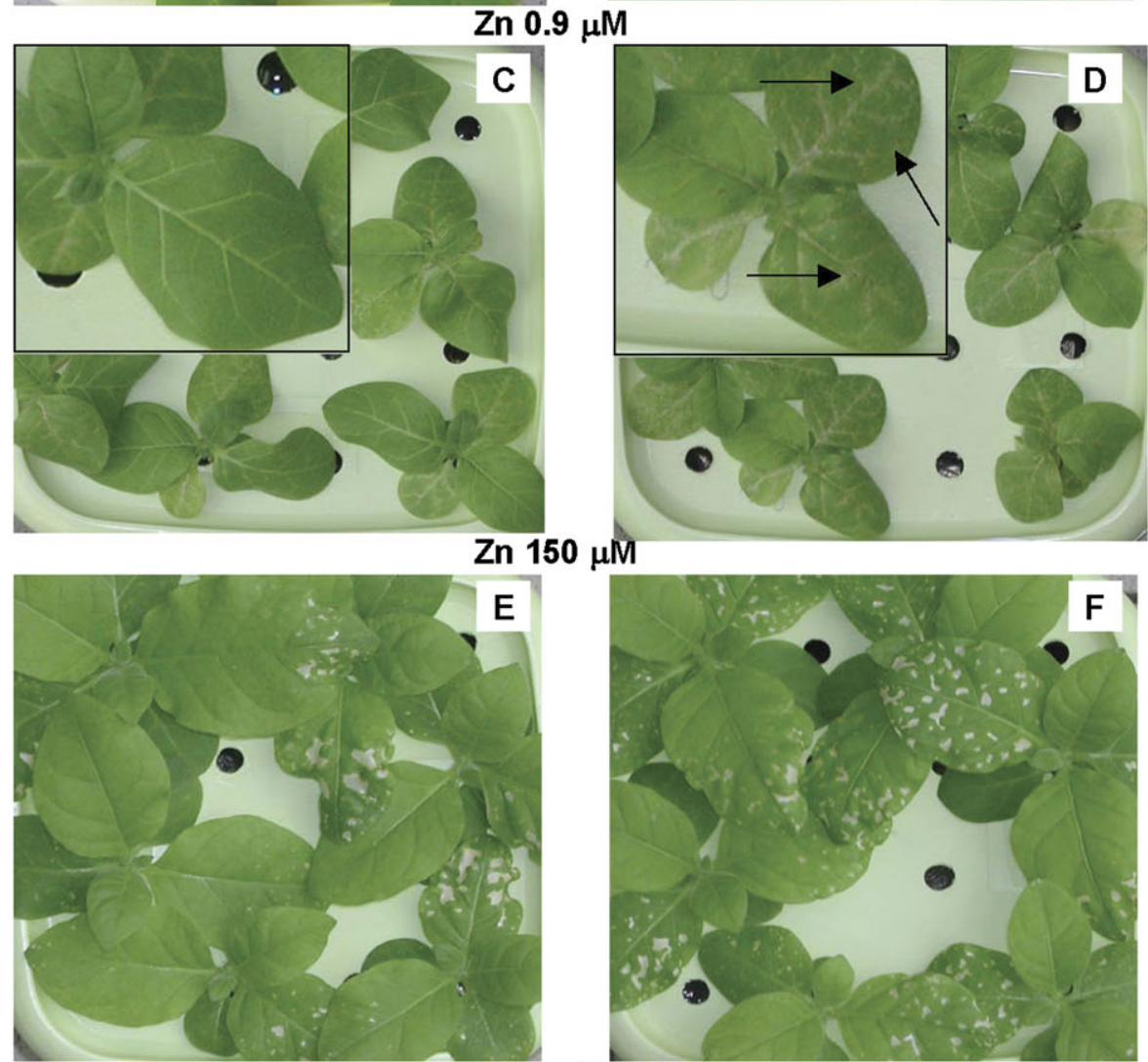

Cd $4 \mu \mathrm{M}$

Fig. 4. Photographs of tobacco plants transformed with AhHMA4 (homozygous $T_{2}$ line) and of wild-type (WT) tobacco (var. Xanthi) grown hydroponically under control conditions and in the presence of high $\mathrm{Zn}(\mathrm{C}, \mathrm{D})$ and high $\mathrm{Cd}(\mathrm{E}, \mathrm{F})$ concentrations in the medium. Plants were grown in quarter-strength Knop's medium containing $0.9 \mu \mathrm{M} \mathrm{ZnCl} 2$ for 4.5 weeks (A, B); grown in quarter-strength Knop's medium for 3.5 weeks and subsequently exposed to $150 \mu \mathrm{M} \mathrm{ZnCl}_{2}$ for $8 \mathrm{~d}(\mathrm{C}, \mathrm{D})$; grown in quarter-strength Knop's medium for 3.5 weeks and subsequently exposed to $4 \mu \mathrm{M} \mathrm{CdCl}_{2}$ for $6 \mathrm{~d}(\mathrm{E}, \mathrm{F})$. Arrows indicate necrotic areas on the leaves. Scale: (A-F) $1 \mathrm{~cm}=1.45$ $\mathrm{cm}$; for the enlargements in (C) and (D), $1 \mathrm{~cm}=2.43 \mathrm{~cm}$.

resulted in a reduction in NtIRTI expression in roots of both transgenic and wild-type plants (Fig. 8).

\section{Discussion}

In studies aimed at the genetic modification of shoot:root metal partitioning for biotechnological purposes (e.g biofortification or phytoremediation), a variety of genes encod- ing membrane transport proteins or proteins involved in the biosynthesis of heavy metal-cation complexing compounds were introduced into host plants, most often under the control of the strong constitutive CaMV 35S promoter (Pilon-Smits and Pilon, 2002). Different from these approaches, in this study $A h H M A 4$ was expressed under the control of its native promoter, which governs cell-typespecific expression in Arabidopsis species and is at least as strong as the $35 \mathrm{~S}$ promoter (Hanikenne et al., 2008) in the 


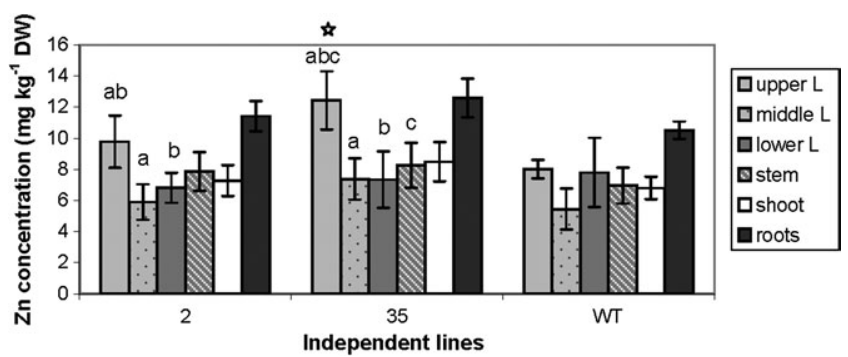

Fig. 5. Zinc accumulation in wild-type and AhHMA4-transformed tobacco lines upon long-term growth under low-Zn conditions. Shown are zinc concentrations in the upper leaves (five leaves counting from the top), the middle leaves (four to five leaves below), the lower leaves (five leaves further below), the stems, the shoots (in all leaves and the stem), and the roots of 8-week-old tobacco plants transformed with AhHMA4 (homozygous lines, $\mathrm{T}_{2}$ generation) or wild-type (WT) tobacco (var. Xanthi) grown hydroponically in quarter-strength Knop's medium for 1 week and subsequently transferred to low $\mathrm{Zn}$ medium $(0.4 \mu \mathrm{M})$ for 5 weeks. Values correspond to arithmetic means $\pm \mathrm{SD}(n=5)$; within each plant line statistically significant difference in $\mathrm{Zn}$ concentrations between upper, middle, and lower leaves are marked by the same letters; within the same categories values significantly different from the respective WT are highlighted by asterisks $(P \leqslant 0.05)$, (evaluated by Student's $t$ test).

heterologous tobacco. Indeed, it was demonstrated here that the AhHMA4-promoter is able to direct AhHMA4 mRNA production in a rather distantly related plant species, tobacco (Fig. 1). In tobacco, however, there was Zn-dependent regulation of AhHMA4 transcript levels in roots, with a suppression of transcript levels upon $\mathrm{Zn}$ resupply compared with plants that remained in $\mathrm{Zn}$ deficient growth conditions (Fig. 8). By contrast, in $A$. halleri, there was little or no metal-supply dependence of AhHMA4 expression levels (Talke et al., 2006; Hanikenne et al., 2008).

\section{Expression of AhHMA4p1::AhHMA4 in tobacco generates differing patterns of root/shoot partitioning of micronutrient zinc and non-essential cadmium dependent on metal supply}

Expression of $A h H M A 4_{p 1}: \because A h H M A 4$ in tobacco did not contribute to one uniform pattern of $\mathrm{Zn}$ and $\mathrm{Cd}$ root/shoot partitioning across a range of metal supplies. $\mathrm{Zn}$ accumulation in transgenic plants depended on the $\mathrm{Zn}$ concentration in the hydroponic medium and, consequently, on plant $\mathrm{Zn}$ status (Figs 2, 3). Compared with the wild type, enhanced accumulation of $\mathrm{Zn}$ in the youngest leaves was observed upon prolonged cultivation of transgenic plants in $0.4 \mu \mathrm{M}$ $\mathrm{Zn}$ (Fig. 5). In entire shoots, transgenic plants contained lower $\mathrm{Zn}$ concentrations than the wild type when grown under control conditions (Fig. 2B) or similar $\mathrm{Zn}$ concentrations when grown under low- or high-Zn conditions (Figs 3 , 5). In wild-type $A$. thaliana and $A$. halleri, net partitioning of $\mathrm{Zn}$ to the shoots is also dependent on the external Zn supply (Talke et al., 2006). However, higher
HMA4 expression in $A$. halleri than in $A$ thaliana, was associated with substantially higher shoot:root $\mathrm{Zn}$ concentration ratios in $A$. halleri as well as shoot $\mathrm{Zn}$ concentrations across the entire range of $\mathrm{Zn}$ concentrations in the medium (0.01-100 $\mu \mathrm{M} \mathrm{Zn).} \mathrm{By} \mathrm{contrast,} \mathrm{introduction} \mathrm{of} \mathrm{the}$ AhHMA4p $p_{1}:$ AhHMA4 construct into the tobacco genome overall did not result in significantly higher $\mathrm{Zn}$ accumulation in shoot tissues when compared with the wild type. There are several possible scenarios to explain this. It is likely, that the altered metal status in tobacco cells expressing $A h H M A 4$, triggers homeostatic mechanisms that counteract the effects of AhHMA4 expression. Another possibility is that, in tobacco, the AhHMA4 promoter might respond to environmental stimuli not explicitly tested here in a different manner when compared to Arabidopsis species, or might be less active (Talke et al., 2006; Hanikenne et al., 2008). This study provided the first circumstantial evidence for the former possibility (Fig. 7), but did not test the latter one. However, the $\mathrm{Zn}$ supplydependent modifications detected in shoot:root $\mathrm{Zn}$ partitioning in transgenic tobacco plants did not correlate with the regulation of AhHMA4 transcript levels in tobacco (Figs 7, 8), but might be related to the $\mathrm{Zn}$-dependent regulation of other metal homeostasis genes in the transgenic plants, which was not present, or much less pronounced, in the wild type (see Fig. 7).

Moreover, AhHMA4 may be active in tobacco cell types different from those in Arabidopsis. AhHMA4 1 1-3-GUS ( $\beta$-glucuronidase) reporter analysis in transformed $A$. thaliana as well as in situ hybridization demonstrated a spatial and tissue-specific expression pattern highly similar to that detected in the closely related $A$. halleri (Hanikenne et al., 2008). However, the localization of AhHMA4 expression in the transgenic tobacco lines is not known. Alternatively or additionally, the AhHMA4 protein might exhibit reduced activity in tobacco because of limited protein production, targeting or activation. This remains to be tested.

Among other factors, the dose-dependent alteration of the zinc accumulation pattern in transgenic plants could also result from modification of the endogenous metal homeostasis network due to AhHMA4 expression. To date, little is known about the root $\mathrm{Zn}$ uptake systems of tobacco. IRT1 from Nicotiana tabacum was cloned and partly characterized (Eide et al., 1996). It is known that IRT1 proteins from various plant species are not specific uptake systems for the primary substrate iron (as a part of the strategy $\mathrm{I} \mathrm{Fe}$ acquisition), but can transport and act in the accumulation of other divalent cations such as $\mathrm{Zn}^{2+}, \mathrm{Cd}^{2+}$ or $\mathrm{Mn}^{2+}$ (Eide et al., 1996; Korshunova et al., 1999; Vert et al., 2002). Here, NtIRT1 transcript levels were found to be up-regulated specifically in transgenic tobacco plants upon exposure to $\mathrm{Zn}$ deficiency or moderately high $\mathrm{Zn}$ concentrations when compared with control conditions or NtIRT1 transcript levels in the wild type (Fig. 7). Consequently, the regulation of NtIRT1 transcript levels in the transgenic tobacco can only partially explain the observed distinct effects of AhHMA4 expression on $\mathrm{Zn}$ accumulation under different $\mathrm{Zn}$ regimes. Different metal uptake systems 

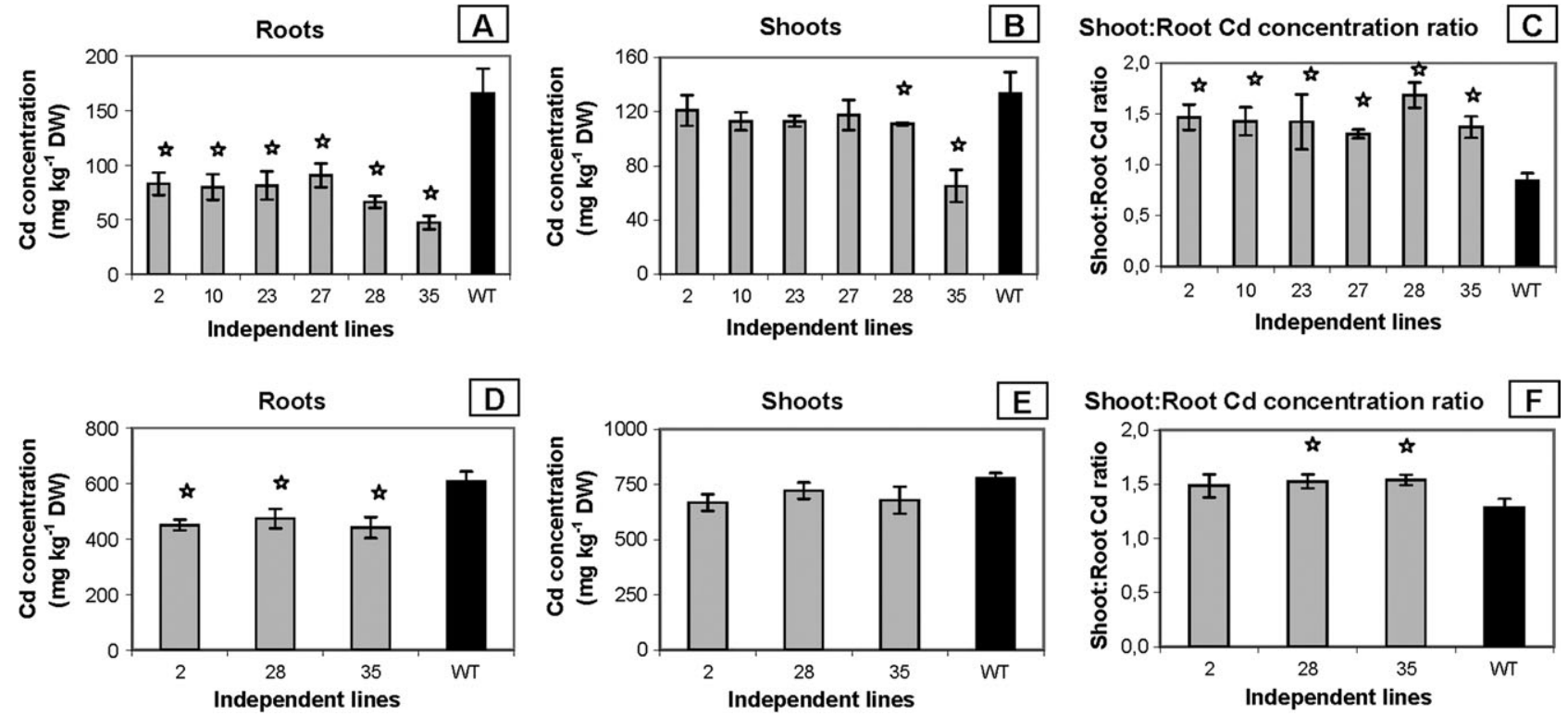

Fig. 6. Cadmium accumulation in wild-type and AhHMA4-transformed tobacco lines upon growth in moderate and high Cd concentrations. Shown are cadmium concentrations in the roots, the shoots, and the shoot:root ratios of cadmium concentrations in 6-week-old tobacco plants transformed with AhHMA4 (homozygous $T_{2}$ lines) and wild-type (WT) tobacco (var. Xanthi) grown hydroponically in quarter-strength Knop's medium for 3.5 weeks and subsequently exposed to $0.25 \mu \mathrm{M} \mathrm{CdCl}$ for $4 \mathrm{~d}(\mathrm{~A}-\mathrm{C})$ or $4 \mu \mathrm{M}$ $\mathrm{CdCl}_{2}$ for $6 \mathrm{~d}(\mathrm{D}-\mathrm{F})$. Lines 10, 23, and 27 are heterozygous $\left(\mathrm{T}_{1}\right)$; lines 2, 28, and 35 are homozygous $\left(\mathrm{T}_{2}\right)$. Values correspond to arithmetic means $\pm S D(n=5)$; those significantly different from WT are indicated by an asterisk $(P \leqslant 0.05)$ (evaluated by Student's $t$ test).

A.

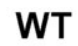

B. 0.4

0.9

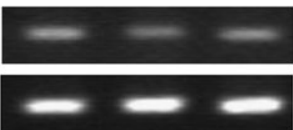

AhHMA4 \#2
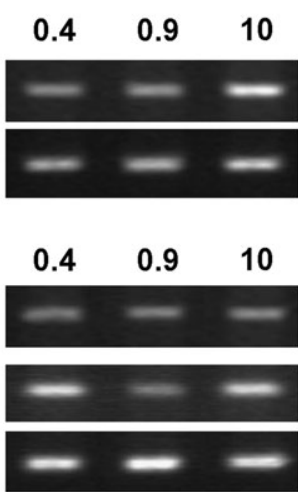

AhHMA4 \#35
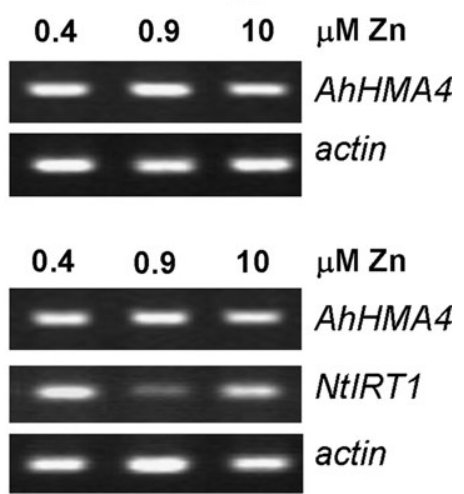

Fig. 7. RT-PCR analysis of AhHMA4 and NtIRT1 transcript levels wild-type and AhHMA4-transformed tobacco lines grown under different $\mathrm{Zn}$ regimes. Shown are gel images of ethidium-bromide stained PCR products of AhHMA4 and NtIRT1 for leaves (A) and roots (B) of AhHMA4-transformed plants (homozygous lines no. 2 and 35, $T_{2}$ ) and the wild-type (WT) plants grown hydroponically in quarterstrength Knop's medium supplemented with 0.4, 0.9, and $10 \mu \mathrm{M} \mathrm{ZnCl}_{2}$. Bottom panels show the PCR product for actin as a constitutively expressed control gene.

might contribute or be prevalent for $\mathrm{Zn}$ uptake in tobacco plants. In the future, it will also be important to examine the regulation of expression of Zn-deficiency responsive tobacco genes, for example, homologues of AtIRT3 and AtZIP4, so far not cloned in tobacco. As shown by Hanikenne et al. (2008), the significant up-regulation of both these genes in the roots of $A$. halleri, which is a consequence of the high level of AhHMA4 expression in this species, may contribute to $\mathrm{Zn}$ hyperaccumulation. An increase in IRT3 and ZIP4 transcript levels also accompanied the recapitulation of $\mathrm{Zn}$ distribution to the xylem characteristic of $A$. halleri in transgenic $A$. thaliana expressing AhHMA4.

There was only a very limited similarity between the modifications of micronutrient $\mathrm{Zn}$ and non-essential toxic $\mathrm{Cd}$ accumulation in transformed tobacco. Cd accumulation in roots was strongly reduced in transgenic tobacco lines at sub-toxic external $\mathrm{Cd}$ concentrations and detectably reduced at toxic external $\mathrm{Cd}$ concentrations, whereas there was little change in the shoots compared with the wild type (Fig. 6). Thus, a larger proportion of total cadmium in the plant was allocated to the shoots, leading to an increased 


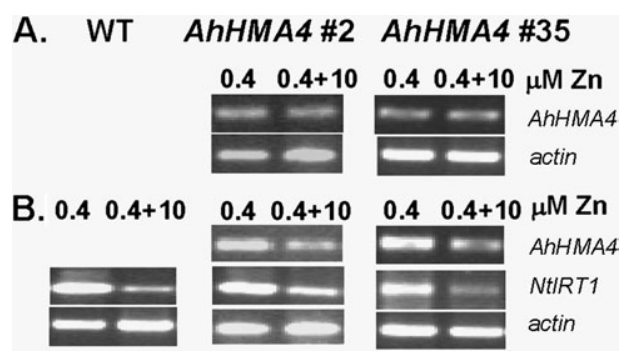

Fig. 8. RT-PCR analysis of AhHMA4 and NtIRT1 transcript levels in Zn-deficient wild-type and AhHMA4-transformed tobacco lines without and with $1 \mathrm{~d}$ of $\mathrm{Zn}$ re-supply. Shown are gel images of ethidium-bromide stained PCR products of AhHMA4 and NtIRT1 for leaves $(A)$ and roots $(B)$ of AhHMA4-transformed plants (homozygous lines no. 2 and 35, $T_{2}$ generation) and wild-type (WT) plants grown hydroponically in quarter-strength Knop's medium containing low $0.4 \mu \mathrm{M} Z \mathrm{Z}$ for 1 week and subsequently in medium containing $10 \mu \mathrm{M} \mathrm{ZnCl}_{2}$ for $1 \mathrm{~d}$. Bottom panels show the PCR product for actin as a constitutively expressed control gene.

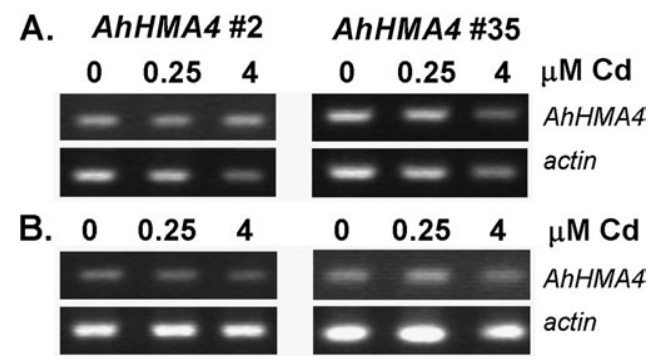

Fig. 9. RT-PCR analysis of AhHMA4 transcript levels in AhHMA4transformants cultivated in the presence of different $\mathrm{Cd}$ concentrations in the medium. Shown are gel images of ethidium-bromide stained PCR products for leaves (A) and roots (B) of AhHMA4transformed plants (homozygous lines no. 2 and $35, T_{2}$ generation) grown hydroponically in quarter-strength Knop's medium supplemented with $0,0.25$ and $4 \mu \mathrm{M} \mathrm{CdCl} 2$ for 3.5 weeks. Bottom panels show the PCR product for actin as a constitutively expressed control gene.

shoot:root ratio of $\mathrm{Cd}$ concentrations (Fig. 6C, F), as expected, based on the known functions of $A h H M A 4$ and AtHMA4 (Hussain et al., 2004; Hanikenne et al., 2008). This suggests that, among other processes, such as possibly $\mathrm{Cd}$ export from the root symplast into the apoplast outside the xylem, AhHMA4 expression in tobacco did contribute to root-to-shoot $\mathrm{Cd}$ transport. At toxic external $\mathrm{Cd}$ concentrations, the contribution of non-specific $\mathrm{Cd}$ transport though a variety of pathways might increase, thus decreasing the contributions of specific transport systems such as $A h H M A 4$ (Fig. 6D-F).

In general, the commonality among the alterations in $\mathrm{Cd}$ and $\mathrm{Zn}$ accumulation by transgenic tobacco plants expressing AhHMA4 examined in this paper lies in their dose dependence. The importance of the cadmium dose in its root-to-shoot partitioning in transgenic plants was also underlined by Korenkov et al. (2007) demonstrating the difference between AtCAX2 and AtCAX4 expressing to- bacco cultivated in media containing $0.02 \mu \mathrm{M} \mathrm{Cd}$ (more $\mathrm{Cd}$ was retained in the roots) and $3 \mu \mathrm{M} \mathrm{Cd}$ (higher $\mathrm{Cd}$ in both roots and shoots). It appears that the introduction of a transgene into a plant does not produce a uniform trait regardless of the growth conditions, but instead, the effect of transgenes is highly dependent on the metal level in the medium. Interestingly, the most pronounced differences in $\mathrm{Zn}$ and $\mathrm{Cd}$ accumulation between transgenic and wild-type plants (although qualitatively different) due to the AhHMA4 expression, were detected at low exposure to both metals. In general, at high external concentrations, accumulation patterns in transgenics became similar to those of the wild type. The mechanisms underlying such phenomena may be similar to those behind the suppression of the $A$. thaliana double mutant hma2/hma4 nutritional deficiency phenotype (Hussain et al., 2004), which was solely compensated by increasing the level of $\mathrm{Zn}$ (up to $10 \mu \mathrm{M}$ in the agar growth medium). The phenotypic complementation of the double mutant by the addition of high external $\mathrm{Zn}$ is possibly due to the involvement of a variety of low-affinity transporters, or even a process broadly referred to as 'exclusion breakdown' upon a supply of a metal excess. Finally, in agreement with the results obtained in tobacco expressing AhHMA4 in this study, Hanikenne et al. (2008) suggested, based on their characterization of transgenic $A$. thaliana expressing $A h H M A 4$, that this gene is necessary, but not sufficient to generate the metal hyperaccumulation phenotype.

\section{AhHMA4p1::AhHMA4 expression in tobacco enhances sensitivity to both zinc and cadmium}

Even if $A h H M A 4$ is expressed in transgenic tobacco plants in the same cell types as in Arabidopsis and the encoded protein exhibits full activity, AhHMA4 expression is likely to be necessary but not sufficient for hyperaccumulation and full $\mathrm{Zn}$ and $\mathrm{Cd}$ tolerance, similar to the earlier conclusions concerning AhHMA4 expression in A. thaliana (Hanikenne et al., 2008). As shown in this study, the expression of $A h H M A 4$ in tobacco resulted in enhanced $\mathrm{Zn}$ sensitivity (Fig. 4) although at harvest, the final $\mathrm{Zn}$ concentration was approximately at the wild-type level (Fig. 3). To compare, heterologous expression of AhHMA4 in $A$. thaliana under its native promoter also resulted in higher zinc sensitivity, but when expressed under the control of the $35 \mathrm{~S}$ promoter, an increase in $\mathrm{Zn}$ and $\mathrm{Cd}$ tolerance was noted in transgenic $A$. thaliana lines (Hanikenne et al., 2008). These two types of transformants also differed in their $\mathrm{Zn}$ accumulation patterns. Higher $\mathrm{Zn}$ sensitivity of AhHMA4 $_{p 1}::$ AhHMA4-transformed A. thaliana was accompanied by slightly elevated shoot $\mathrm{Zn}$ concentration (1-16fold), whereas higher $\mathrm{Zn}$ tolerance of $\mathrm{p} 35 \mathrm{~S}:: A h H M A 4$ plants was associated with unaltered or reduced shoot $\mathrm{Zn}$ levels (Hanikenne et al., 2008). Only partially in agreement with these data are the results obtained by Verret et al. (2004). This study, which was based on the characterization of only a single transgenic line, reported enhanced $\mathrm{Zn}$ tolerance in 35S-AtHMA4 overexpressor lines, but 
also enhanced shoot $\mathrm{Zn}$ concentrations. The fact that increased $\mathrm{Zn}$ sensitivity was observed in both transgenic AhHMA4 $_{p 1}: \because$ AhHMA4 A. thaliana (Hanikenne et al., 2008) and tobacco plants, whereas the use of a $35 \mathrm{~S}$ promoter enhanced $\mathrm{Zn}$ tolerance (Verret et al., 2004; Hanikenne et al., 2008) suggests a crucial role for the cell-type-specific expression and the transcriptional regulation of the introduced transgene.

As shown by Hanikenne et al. (2008), not only the full extent of $\mathrm{Zn}$ hypertolerance but also, and to a somewhat larger extent, Cd hypertolerance of $A$. halleri depends on AhHMA4. The A. halleri HMA4 RNAi lines exhibited a dramatically enhanced sensitivity to cadmium relative to wild-type $A$. halleri plants. However, the transfer of AhHMA4 $_{p 1} \because: A h H M A 4$ to A. thaliana slightly lowered the tolerance to this heavy metal. The AhHMA4-dependent increase in $\mathrm{Cd}$ sensitivity in the leaves of transgenic tobacco lines suggests that AhHMA4 expression in tobacco results in $\mathrm{Cd}$ accumulation at sensitive sites lacking sufficient $\mathrm{Cd}$ detoxification capacity, very similar to the earlier observations in AhHMA4-expressing A. thaliana (Hanikenne et al., 2008). Alternatively, cellular $\mathrm{Zn}$ export by AhHMA4, known to be localized at plasma membrane (Courbot et al., 2007), may cause a local signal of nutrient deficiency in the respective cells in transgenic tobacco and $A$. thaliana, which in turn might trigger the release of divalent transition metal nutrient cations from their stores, in particular vacuoles. This could ultimately lead to an increase in cytosolic cadmium concentrations. For example, the increase in cytosolic cadmium was the cause of higher $\mathrm{Cd}$ sensitivity of $N R A M P 3$ overexpressing $A$. thaliana plants due to the nonspecific release of $\mathrm{Cd}$ from the vacuoles through this transporter (Thomine et al., 2003).

\section{Biotechnology perspective}

In summary, transgenic tobacco expressing AhHMA4 under the control of the native $A$. halleri promoter exhibited a complex pattern of alterations in $\mathrm{Zn}$ and $\mathrm{Cd}$ accumulation when compared with the wild type. The intended increase in leaf metal concentrations of tobacco plants expressing AhHMA4, when compared to the wild type, was only observed when a pool of the youngest (top five) leaves were analysed from transgenic plants grown under low-Zn conditions for 5 weeks (Fig. 5), but not in entire shoots of tobacco plants grown under various $\mathrm{Zn}$ conditions (deficiency, control, and excess; Figs 2, 3, 5). For biotechnology purposes, an improved understanding of the molecular mechanisms resulting in such complex dose-dependent effects of transgenes on root/shoot $\mathrm{Zn}$ and $\mathrm{Cd}$ partitioning in transformed plants is vital, but currently very difficult to achieve in plants of which the metal homeostasis network is less well understood than that of the model plant Arabidopsis thaliana. For a future understanding of this phenomenon, it is therefore important to take into account that plant transcript profiles are likely to be specific and different in plants of low, medium, and high $\mathrm{Zn}$ status (Puig and Peñarrubia, 2009), as well as in plants exposed to low and high levels of a stress factor, for example, toxic cadmium (Kacperska, 2004). Thus, the phenotype of a transgenic plant exposed to a range of $\mathrm{Zn}$ and $\mathrm{Cd}$ concentrations probably results from the interplay between the transgene activity and the very different molecular backgrounds of the host plant at varying metal levels in the medium.

Although, in tobacco, the expression of HMA4 from the $\mathrm{Zn} / \mathrm{Cd}$ hyperaccumulator $A$. halleri under its native promoter did not cause a dramatic increase in the translocation of the micronutrient zinc from the roots to the shoots, the results obtained are interesting from a biofortification perspective. The transformed plants were more efficient in the translocation of the micronutrient zinc to rapidly growing young leaves of plants grown under zinc deficiency $(0.4 \mu \mathrm{M})$. In addition, AhHMA4 expression drastically reduced shoot concentrations of the non-essential, toxic cadmium, and the decrease of contaminants in crop plants is an important secondary goal in biofortification that has been hard to address (Krämer, 2009).

\section{Acknowledgements}

This work was supported by the EU through its Sixth Framework Programme for RTD (contract no FOOD-CT2006-016253). It reflects only the author's views. The Community is not liable for any use that may be made of the information contained therein.

\section{References}

Antosiewicz DM, Hennig J. 2004. Overexpression of LCT1 in tobacco enhances the protective action of calcium against cadmium toxicity. Environmental Pollution 129, 237-245.

Antosiewicz DM. 2005. Study of calcium-dependent lead-tolerance on plants differing in their level of Ca-deficiency tolerance.

Environmental Pollution 134, 23-34.

Connolly EL, Fett JP, Guerinot ML. 2002. Expression of the IRT1 metal transporter is controlled by metals at the levels of transcript and protein accumulation. The Plant Cell 14, 1347-1357.

Courbot M, Willems G, Motte P, Arvidsson S, Roosens N, Saumitou-Laprade P, Verbruggen N. 2007. A major quantitative trait locus for cadmium tolerance in Arabidopsis halleri colocalizes with HMA4, a gene encoding a heavy metal ATPase1. Plant Physiology 144, 1052-1065.

Eide D, Broderius M, Fett J, Guerinot ML. 1996. A novel ironregulated metal transporter from plants identified by functional expression in yeast. Procedings of the National Academy of Sciences, USA 93, 5624-5628.

Hanikenne M, Talke IN, Haydon MJ, Lanz C, Nolte A, Motte P, Kroymann J, Weigel D, Krämer U. 2008. Evolution of metal hyperaccumulation required cis-regulatory changes and triplication of HMA4. Nature 453, 391-395.

Horsch RB, Fry JE, Hoffman NE, Eichholtz D, Rogers SG, Fraley RT. 1985. A simple and general method for transferring genes into plants. Science 227, 1229-1231. 
Hussain D, Haydon MJ, Wang Y, Wong E, Sherson SM, Young J, Camakaris J, Harper JF, Cobbett CS. 2004. P-type ATPase heavy metal transporters with roles in essential zinc homeostasis in Arabidopsis. The Plant Cell 16, 1327-1339.

Hodoshima H, Enomoto Y, Shoji K, Shimada H, Goto F, Yoshihara T. 2008. Differential regulation of cadmium-inducible expression of iron-deficiency-responsive genes in tobacco and barley. Physiologia Plantarum 129, 622-634.

Kacperska A. 2004. Sensor type in signal transduction pathways in plant cells responding to abiotic stressors: do they depend on stress intensity? Physiologia Plantarum 112, 159-168.

Korenkov V, Hirschi K, Crutchfield JD, Wagner GJ. 2007. Enhancing tonoplast $\mathrm{Cd} / \mathrm{H}$ antiport activity increases $\mathrm{Cd}, \mathrm{Zn}$, and $\mathrm{Mn}$ tolerance, and impacts root/shoot Cd partitioning in Nicotiana tabacum L. Planta 226, 1379-1387.

Korshunova YO, Eide D, Clark WG, Guerinot ML, Pakrasi HB. 1999. The IRT1 protein from Arabidopsis thaliana is a metal transporter with a broad substrate range. Plant Molecular Biology 40, 37-44.

Krämer U. 2005. Phytoremediation: novel approaches to cleaning up polluted soils. Current Opinion in Biotechnology 16, 133-141.

Krämer U, Talke IN, Hanikenne M. 2007. Transition metal transport. FEBS Letters 581, 2263-2272.

Krämer U. 2009. The dillema of controlling heavy metal accumulation in plants. New Phytologist 181, 3-5.

Kunze R, Frommer WB, Flüge U-I. 2002. Metabolic engineering of plants: the role of membrane transport. Metabolic Engineering 4, 57-66.

Lee S, An G. 2009. Over-expression of OsIRT1 leads to increased iron and zinc accumulation in rice. Plant, Cell and Environment 32, 408-416.

Mills RF, Krijger GC, Baccarini BJ, Hall JL, Williams LE. 2003. Functional expression of AtHMA4, a $\mathrm{P}_{1 \mathrm{~B}} \mathrm{ATPase}$ od the $\mathrm{Zn} / \mathrm{Co} / \mathrm{Cd} / \mathrm{Pb}$ subclass. The Plant Journal 35, 164-176.

Mills RF, Francini A, daRocha PSCF, Bacarini PJ, Aylett M, Krijger GC, Williams LE. 2005. The plant P-1B-type ATPase AtHMA4 transports $\mathrm{Zn}$ and $\mathrm{Cd}$ and plays a role in detoxification of transition metals supplied at elevated levels. FEBS Letters 579, 783-791.

Murashige T, Skoog F. 1962. A revised medium for rapid growth and bioassays with tobacco tissue cultures. Physiologia Plantarum 15, 473-497.

Palmgren MG, Clemens S, Williams LE, Krämer U, Borg S, Schjorring JK, Sanders D. 2008. Zinc biofortification of cereals; problems and solutions. Trends in Plant Science 13, 464-473.

Pilon-Smits E, Pilon M. 2002. Phytoremediation of metals using transgenic plants. Critical Review in Plant Science 21, 433-456.
Puig S, Peñarrubia L. 2009. Placing metal micronutrients in context: transport and distribution in plants. Current Opinion in Plant Biology 12, 299-306.

Talke IN, Hanikenne M, Krämer U. 2006. Zinc-dependent global transcriptional control, transcriptional deregulation, and higher gene copy number for genes in metal homeostasis of the hymeraccumulator Arabidopsis halleri. Plant Physiology 142, 148-167.

Thomine S, Lelièvre F, Debarbieux E, Schroeder JF, BarbierBrygoo H. 2003. AtNRAMP3, a multispecific vacuolar metal transporter involved in plant responses to iron deficiency. The Plant Journal 34, 685-695.

Verkleij JAC, Golan-Goldhirsh A, Antosiewicz DM, Schwitzguébel J-P, Schröder P. 2009. Dualities in plant tolerance to pollutants and their uptake and translocation to the upper plant parts. Environmental and Experimental Botany 67, 10-22.

Verret F, Gravot A, Auroy P, Leonhardt N, David P, Nussaume L, Vavasseur A, Richaud P. 2004. Overexpression of AtHMA4 enhances root-to-shoot translocation of zinc and cadmium and plant metal tolerance. FEBS Letters 576, 306-312.

Verret F, Gravot A, Auroy P, Preveral S, Forestier C, Vavasseur A, Richaud P. 2005. Heavy metal transport by AtHMA4 involves the $\mathrm{N}$-terminal degenerated metal binding domain and the C-terminal His ${ }_{11}$ stretch. FEBS Letters 579, 1515-1522.

Vert G, Grotz N, Dédaldéchamp F, Gaymard F, Guerinot M-L, Briat J-F, Curie C. 2002. IRT1, an Arabidopsis transporter essential for iron uptake from the soil and for plant growth. The Plant Cell 14, 1223-1233.

Wojas S, Clemens S, Hennig J, Skłodowska A, Kopera E, Schat H, Bal W, Antosiewicz DM. 2008. Overexpression of phytochelatin synthase in tobacco: distinctive effects of AtPCS1 and CePCS genes on plant response to cadmium. Journal of Experimental Botany 59, 2205-2219.

Wojas S, Hennig J, Plaza S, Geisler M, Siemianowski O, Skłodowska A, Ruszczyńska A, Bulska E, Antosiewicz DM. 2009. Ectopic expression of Arabidopsis ABC transporter MRP7 modifies cadmium root-to-shoot transport and accumulation. Environmental Pollution 157, 2781-2789.

Wojas S, Ruszczyńska A, Bulska E, Wojciechowski M, Antosiewicz DM. 2007. $\mathrm{Ca}^{2+}$-dependent plant response to $\mathrm{Pb}^{2+}$ is regulated by LCT1. Environmental Pollution 147, 584-592.

Wong CK, Cobbett CS. 2009. HMA P-type ATPases are the major mechanism for root-to-shoot translocation in Arabidopsis thaliana. New Phytologist 181, 71-78.

Zhao F-J, McGrath SP. 2009. Biofortification and phytoremediation. Current Opinion in Plant Biology 12, 373-380. 